\title{
Differentiation of $\mathrm{N}$-acetyltransferase 2 (NAT2) rapid and intermediate acetylator based on genotype and urinary assay
}

\section{Rika Yuliwulandari ${ }^{1,2,3}$, Kinasih Prayuni², Herman Usman4, Qomariyah Sachrowardi5 ${ }^{4}$, and Katsushi}

$$
\text { Tokunaga }{ }^{6}
$$

1. Department of Pharmacology, Faculty of Medicine, YARSI University, Indonesia

2. Genomic Medicine Research Center, YARSI Research Institute, YARSI University, Indonesia

3. The Indonesia Pharmacogenomics Working Group, Indonesia

4. Department of Biochemistry, Faculty of Medicine, YARSI University, Indonesia

5. Department of Physiology, Faculty of Medicine, YARSI University, Indonesia

6. Department of Human Genetics, Graduate School of Medicine, The University of Tokyo, Japan

\section{RESEARCH}

Please cite this paper as: Yuliwulandari R, Prayuni K, Usman $H$, Sachrowardi $Q$, Tokunaga K. Differentiation of $\mathrm{N}$ acetyltransferase 2 (NAT2) rapid and intermediate acetylator based on genotype and urinary assay. AMJ 2017;10(10):879-883.

https://doi.org/10.21767/AMJ.2017.3105

\section{Corresponding Author:}

Rika Yuliwulandari, MD., Ph.D

Jl. Letjen Suprapto, Cempaka Putih, Jakarta 10510

Indonesia

Email: rika.yuliwulandari@yarsi.ac.id

\section{ABSTRACT}

\section{Background}

Determination of the acetylator type of NAT2 generally can be predicted based on genotype data from the NAT2 database. However, in some reported studies, it does not show 100 per cent concordance with the phenotype based on urinary assay. The assay generally only differentiates the rapid and slow acetylator but does not consider the intermediate one.

\section{Aims}

We conducted this study to define the phenotype of NAT2 based on both genotyping and urinary assay and to determine the concordance rate between both methods in rapid and intermediate acetylator groups.

\section{Methods}

NAT2 genotyping was done using the PCR-direct sequencing in a total of 30 healthy subjects. However, for the NAT2 phenotypes we only selected 19 healthy subjects that carry rapid or intermediate acetylator genotype, without involving slow acetylator phenotype. The assay was done by measuring the ratios of urinary caffeine metabolites following controlled diet exposure.

Results

Both data obtained from genotyping and urinary assay showed 2 samples that belonged to the rapid acetylator and 17 samples that belonged to the intermediate acetylator. The mean metabolic ratio of the rapid acetylator group showed a higher level (0.5) than the intermediate group (0.28). The predicted acetylation status of NAT2 SNPs from genotyping was matched with the phenotype which was determined by urinary analysis.

\section{Conclusion}

Our result showed a 100 per cent concordance of NAT2 phenotype based on the genotyping and urinary assay. Based on this study we suggest that NAT2 phenotype based on genotyping method is simpler and faster, rather than using the urinary assay that is more laborious and costly.

\section{Key Words}

NAT2 genotyping, NAT2 phenotyping, caffeine metabolite, urinary analysis

\section{What this study adds:}

\section{What is known about this subject?}

Differentiation the phenotype of NAT2 based on both the genotyping and urinary assay showed 100 per cent concordance. 


\section{What new information is offered in this study?}

We differentiate between the rapid and intermediate NAT2 acetylator type, whereas several reports only differentiate between the rapid and slow acetylator, supporting the NAT2 trimodal distribution.

3. What are the implications for research, policy, or practice?

Determination of the NAT2 phenotype based on genotyping is simpler and faster compared to the urinary assay that is more laborious and costly.

\section{Background}

$\mathrm{N}$-acetyltransferase 2 (NAT2) is a well-known phase II enzyme that is responsible for the acetylation of many arylamine and hydrazine drugs, as well as for a number of toxins and known carcinogens present in the diet, cigarette smoke and the environment. ${ }^{1}$ NAT2 is localized in human chromosome 8p22 and is mainly expressed in liver, small intestine and colon. ${ }^{2}$ It is produced by a single, intronless protein-coding exons of $870 \mathrm{bp}$ open reading frames encoding 290 amino acids. ${ }^{3}$

Human N-acetyltransferase 2 (NAT2) phenotyping is based on the quantification of urinary caffeine metabolites and on the calculation of metabolic ratios after the intake of a standardized caffeine (1,3,7-trimethylxanthine) dose. It has been established that Nyéki et al. ${ }^{4}$ method was the most used analytical procedure for measuring the NAT2 activity. This method was modified method by Grant et al. ${ }^{5}$ and represents a substantial improvement, since a single analysis and the minimal urine sample treatment, enables the simultaneous quantification of five caffeine metabolites including 5-acetylamino-6-formylamino-3- methyluracil (AFMU), 5-acetylamino-6-amino-3-methyluracil (AAMU), 1methylxanthine (1X), 1-methyluric acid (1U), 1,7dimethyluric acid (17U) necessary for the phenotyping of NAT2, cytochrome P450 isoenzyme 1A2 (CYP1A2) and xanthine oxidase $(\mathrm{XO})$.

Polymorphisms in NAT2 were responsible for the acetylation efficiency of a wide variety of xenobiotics compounds as well as therapeutic drugs. It has been regarded as important markers for prediction of the drug detoxification capability in individuals. Individuals can be classified as slow or rapid acetylators, on the basis of their NAT2 genotype, ${ }^{6,7}$ although some authors consider a third intermediate category. ${ }^{1,8,9}$ Slow (SA), intermediate (IA) and rapid acetylators (RA) consisted of homozygous of two slow alleles, heterozygous between rapid and slow allele and homozygous of two rapid alleles, respectively.,10
In some report, the determination of the acetylation status did not show 100 per cent concordance between the genotype and the phenotype analysis based on the urinary assay. ${ }^{8,11}$ Additionally, the phenotype analysis, usually accommodated only bimodal distribution (slow and rapid group $^{12,13}$ and does not differentiate between the intermediate group from the rapid group. Therefore, in the present study we conducted a study to define the rapid and intermediate NAT2 phenotype based on both genotyping and urinary assay and determine the concordance rate between both methods.

\section{Method}

\section{Sample collection}

A total 30 healthy subjects from previous study ${ }^{14}$ which were subjected to controlled diet exposure participated in the study. This study was done in the Human Genetics Laboratory, University of Tokyo, Japan, YARSI Research Institute and BElab Jakarta. The ethnic background of the patients in this study was Javanese, Sundanese and Betawi. All participants received detailed oral and written explanations concerning the aims of the study and its implications, and gave their written informed consent. The study was approved by the Ethics Committee of the YARSI University.

\section{NAT2 genotyping}

NAT2 genotyping was performed with genomic DNA extracted from peripheral blood EDTA samples using the QIA amp DNA blood mini kit (QIAGEN, Hilden, Germany). PCR was performed to amplify the coding region of NAT2 using our previous published method. ${ }^{14}$ Direct sequencing was performed using a commercial kit (BigDye Terminator v.3.1, Applied Biosystem) with an ABI 310 Genetic Analyzer (Applied Biosystem). Forward and reverse primers used for PCR and direct DNA sequencing were based on our previously published report. ${ }^{14}$ We detected specific NAT2 fragments that contain the following SNPs: rs1041983 [282C>T], $\quad r s 1801280 \quad[341 T>C], \quad r s 1799929 \quad$ [481C>T], rs1799930 [590G>A], rs1208 [803A>G], and rs1799931 [857G>A]. Genotyping data were compiled according to the genotype and allele frequencies estimated from the observed numbers of each specific allele. NAT2 allele and predicted acetylator phenotype were compared to human NAT2 allele database at http://nat.mbg.duth.gr/Human NAT2 alleles_2013.htm. The statistical analyses of the allelic and genotypic frequencies were conducted using a Chisquared test. Haplotype reconstruction was performed using PHASE v2.1.1 software. $^{15}$ 


\section{NAT2 activity measurement}

The functional assays were done by measuring the ratios of the urinary caffeine metabolites Among 30 healthy subjects with NAT2 genotype, we selected 19 healthy subjects with rapid and intermediate acetylator. They were subjected to controlled diet exposure before participating in the study. Urine samples were collected before and 8 hours after a dose of $100 \mathrm{mg}$ Caffeine (Sigma-Aldrich, Missouri, United States). The metabolites 5-acetylamino-6-amino-3methyluracil (AAMU), 1-methylxanthine (1X), 5acetylamino-6-formylamino-3-methyluracil (AFMU) and 1methylurate (1U) were quantified using HPLC method (Hitachi co Ltd, Tokyo, Japan) according to manufacturer's instruction. The NAT2 activity was calculated based on the molar ratio of 5-acetylamino-6-formylamino-3-methyluracil and 1- methylxanthine in urine after caffeine intake $(A F M U+A A M U) /(A F M U+A A M U+1 U+1 X){ }^{4}$

\section{Results}

The allele frequencies and NAT2 allele variant are summarized in Table 1 . We observed 5 different NAT2 allele variant in this study. Based on NAT2 human database (http://nat.mbg.duth.gr/Human NAT2 alleles_2013.htm), NAT2*4 and Nat2*13 are classified as fast acetylator allele, whereas NAT2*5B, NAT2*6A, NAT2*7B are classified as slow acetylator allele. We selected 19 individual with genotypes $\mathrm{NAT} 2 * 4 / * 4, * 4 / * 5 \mathrm{~B}, * 4 / * 6 \mathrm{~A}, * 4 / * 7 \mathrm{~B}$ and $* 6 \mathrm{~A} / * 13$ for further analysis. NAT2*4/*4 was predicted as rapid acetylator, whereas NAT2*4/*5B, *4/*6A, *4/*7B and $* 6 \mathrm{~A} /{ }^{*} 13$ as intermediate acetylator type. The acetylation activities based on urinary analysis with corresponding genotypes were shown in Table 2. It showed a 100 per cent concordance with predicted phenotype that we examined in the study. Our result revealed that the mean metabolic ratio of rapid acetylator group showed a higher level (0.5) than the one of intermediate group (0.28) on the coding region haplotype (Figure 1).

\section{Discussion}

In this study we identified 5 different NAT2 genotype variant. Major alleles found in our study were NAT2*4 as a wild type allele and NAT2*6A with frequency 63 per cent and 66 per cent, respectively (Table 1 ). NAT2*4 is wild type allele and with NAT2*13 is known as rapid acetylator allele. Other variant allele such as NAT2*6A, NAT2*7B and NAT2*5B are categorized as slow acetylator alleles. The distributions of NAT2 allele variant in our result are similar to that previously reported study in Javanese-Sundanese ethnic of Indonesia population ${ }^{14}$ and Malay Ethnic of Indonesia population. ${ }^{16}$ This result also reassembly with the NAT2 allele distribution in Southeast Asian population such as Thailand, India, Malay, Filipino. ${ }^{14}$ The NAT2 slow acetylator phenotypes have been investigated to have association with cancer risk $^{17}$ and isoniazid-induced hepatotoxicity in tuberculosis treatment. ${ }^{18,19}$

Examination on NAT2 activity were using urinary caffeine metabolite analysis that widely used as a non-toxic drug in vivo for predicting acetylator phenotype. ${ }^{8}$ Our urinary analysis result demonstrates the deduced acetylation status from (AFMU+AAMU)/(AFMU+AAMU+1U+1X) ratios assigned to each NAT2 allele combination detected in this study. The ratio of urinary caffeine metabolites in healthy samples showed that metabolic ratio of rapid acetylator group $(0,5)$ was higher than the one of intermediate group $(0,28)$ (Figure 1). NAT2 rapid group are homozygous group consist of rapid allele, whereas NAT2 intermediate group are heterozygous group consist of rapid allele and slow allele. $^{20}$ Study by Zhang et al. ${ }^{21}$ showed that the SNPs in haplotype with slow acetylator allele, reduce the Sulfamethazine $\mathrm{N}$-acetylation activity. This study supported our result that the genotype contained the slow allele displayed slower activity than homozygous rapid genotype.

Genotype *4/*4 homozygous showed the highest NAT2 activity in this study. Additionally, in the intermediate group, the genotype $* 4 / * 5 B$ showed the slowest activity than other intermediate genotypes, whereas genotype *4/*7B showed the highest activity. Previous in vitro study of NAT2 enzyme activity assessed the degree of acetylation activity which varied among NAT2 alleles. NAT2*4 displaying the highest activity and NAT2*5 displaying the lowest; NAT2* 6 and NAT2*7 show activities between NAT2*4 and NAT $2 * 5 .{ }^{22}$

This study confirmed that both genotyping and phenotyping results were in concordance in the Indonesia population. However, differentiation between the NAT2 rapid and the intermediate acetylator, need to be done with larger samples, in order to examine more NAT2 genotype that corresponding to rapid and intermediate acetylator. This study indicated that the differentiation of the NAT2 phenotype had a trimodal distribution. ${ }^{23}$ Additionally, this study also supported the fast deduction of the acetylation status based on the genotyping assay.

\section{Conclusion}

We conclude that the acetylator status prediction using the NAT2 genotype determination on coding region concurred with the result of the caffeine metabolites examination using the urinary analysis to distinguish rapid and intermediate acetylator groups. 


\section{References}

1. García-Martín E. Interethnic and intraethnic variability of NAT2 single nucleotide polymorphisms. Curr Drug Metab. 2008;9:487-497. doi:10.2174/138920008784892155

2. Ruiz JD, Agúndez JAG, Martínez $\mathrm{C}$, et al. NAT2 (Nacetyltransferase 2 (arylamine $\mathrm{N}$-acetyltransferase)). Atlas Genet Cytogenet Oncol Haematol. 2009;13:952955. doi: $10.4267 / 2042 / 44640$

3. Kang TS, Jin SK, Lee JE, et al. Comparison of genetic polymorphisms of the NAT2 gene between Korean and four other ethnic groups. J Clin Pharm Ther. 2009;34:709-718. doi: 10.1111/j13652710.2009.01065.x

4. Nyéki Á, Buclin T, Biollaz J, et al. NAT2 and CYP1A2 phenotyping with caffeine: Head-to-head comparison of $A F M U$ vs. AAMU in the urine metabolite ratios. Br J Clin Pharmacol. 2003;55:62-67. doi: 101.1046/j.13652125.2003.01730.x

5. Grant D, Hughes N, Janezic $S$, et al. Human acetyltransferase polymorphism. Mutat Res. 1997;376:61-70. doi: 10.1016/S0027-5107(97)00026-2

6. Lakkakula S, Pathapati RM, Chaubey G, et al. NAT2 genetic variations among South Indian populations. Human Genome Var. 2014;1:14014. doi: 10.1038/hgv.2014.14. eCollection 2014

7. Chamorro JG, Castagnino JP, Musella RM, et al. The distribution of allelic and genotypic frequencies of $\mathrm{N}$ acetyltransferase- 2 variants in an Argentine population. J Infect Dev Ctries. 2012;6:671-674. doi: 10.3855/jidc. 2111

8. McDonagh EM, Boukouvala S, Aklillu E, et al. PharmGKB summary: very important pharmacogene information for N-acetyltransferase 2. Pharmacogenet Genomics. 2014;24:409-425. doi: 10.1097/FPC. 0000000000000062

9. Yuliwulandari R, Susilowati RW, Wicaksono BD, et al. NAT2 variants are associated with drug-induced liver injury caused by anti-tuberculosis drugs in Indonesian patients with tuberculosis. J Hum Genet. 2016;61:533537. doi: 10.1038/jhg.2016.10

10. Stanley LA, Sim E. Update on the pharmacogenetics of NATs: structural considerations. Pharmacogenomics. 2008;9:1673-1693. doi: 10.2217/14622416.9.11.1673

11. Cascorbi I, Drakoulis N, Brockmoller J, et al. Arylamine Nacetyltransferase (NAT2) mutations and their allelic linkage in unrelated Caucasian individuals: correlation with phenotypic activity. Am J Hum Genet. 1995;57(3):581-592.

12. Rihs HP, John A, Scherenberg $M$, et al. Concordance between the deduced acetylation status generated by high-speed Real-time PCR based NAT2 genotyping of seven single nucleotide polymorphisms and human NAT2 phenotypes determined by a caffeine assay. Clin Chim Acta. 2007;376(1-2):240-243. doi: 10.1016/j.cca.2006.08.010

13. Ruiz JD, Martínez C, Anderson K, et al. The differential effect of NAT2 variant alleles permits refinement in phenotype inference and identifies a very slow acetylation genotype. PLoS One. 2012;7(9):e44629. doi: 10.1371/journal.pone.0044629

14. Yuliwulandari R, Sachrowardi Q, Nishida N, et al. Polymorphisms of promoter and coding regions of the arylamine $\mathrm{N}$-acetyltransferase 2 (NAT2) gene in the Indonesian population: Proposal for a new nomenclature. J Hum Genet. 2008;53(3):201-209. doi:10.1007/s10038-007-0237-

15. M Smith NJ, Donnelly P. A new statistical method for haplotype reconstruction from population data. Am J Hum Genet. 2001;68(4):978-989. doi: 10.1086/319501

16. Susilowati RW, Prayuni K, Razari I, et al. High frequency of NAT2 slow acetylator alleles in the Malay population of Indonesia : an awareness to the anti-tuberculosis drug induced liver injury and cancer. Med J Indones. 2017;25:7-13. doi: 10.13181/mji.v26i1.1563

17. Fernandes MR, de Carvalho DC, dos Santos ÂK, et al. Association of slow acetylation profile of NAT2 with breast and gastric cancer risk in Brazil. Anticancer Res. 2013;33:3683-3689.

18. Yuliwulandari R, Susilowati RW, Wicaksono BD, et al. NAT2 variants are associated with drug-induced liver injury caused by anti-tuberculosis drugs in Indonesian patients with tuberculosis. J Hum Genet. 2016;61:533537. doi: 10.1038/jhg.2016.10

19. Yuliwulandari, R. Farmakogenomik \& Farmakogenetik. Jakarta: FK Universitas YARSI; 2016.

20. Selinski S, Blaszkewicz M, Ickstadt K, et al. Refinement of the prediction of $\mathrm{N}$-acetyltransferase 2 (NAT2) phenotypes with respect to enzyme activity and urinary bladder cancer risk. Arch Toxicol. 2013;87(12):21292139. doi: 10.1007/s00204-013-1157-7

21.Zang $Y$, Doll MA, Zhao $S$, et al. Functional characterization of single-nucleotide polymorphisms and haplotypes of human N-acetyltransferase 2 . Carcinogenesis. 2007;28:1665-1671. doi: 10.1093/carcin/bgm085

22. Hein DW, Doll MA, Rustan TD, et al. Metabolic activation of $\mathrm{N}$-Hydroxyarylamines and $\mathrm{N}$-Hydroxyarylamides by 16 recombinant human NAT2 allozymes: Effects of 7 specific NAT2 nucleic acid substitutions. Cancer Res. 1995;55:3531-3536.

23. Parkin DP, Vandenplas S, Botha FJ, et al. Trimodality of isoniazid elimination: phenotype and genotype in patients with tuberculosis. Am J Respir Crit Care Med. 1997;155(5):1717-22.

doi: 10.1164/ajrccm.155.5.9154882

\section{ACKNOWLEDGEMENTS}

This project was funded by a grant from the Indonesian Directorate General of Higher Education (DIKTI) of the Ministry of Higher Education, Research and Technology of the Republic of Indonesia by Penelitian Terapan Unggulan Perguruan Tinggi (PTUPT) scheme. We thank to Dharma Permana, PhD and to the following institutions/organizations for their support in this project: 
YARSI Foundation, Pasar Rebo General Hospital, BELab Jakarta, YARSI Genomic Medicine Research Group and all participants who participated in this study.

\section{PEER REVIEW}

Not commissioned. Externally peer reviewed.

\section{CONFLICTS OF INTEREST}

The authors declare that they have no competing interests.

\section{FUNDING}

Indonesian Directorate of Higher Education (DIKTI) of Ministry of Higher Education, Research and technology of Republic of Indonesia by Penelitian Terapan Unggulan Perguruan Tinggi (PTUPT) Scheme.

\section{ETHICS COMMITTEE APPROVAL}

Research Ethics Committee, YARSI Research Institute, YARSI University, Ethical Clearence No 020/KEP-UY/BIA/VIII/2014.

Figure 1: NAT2 Acetylation capacity between Intermediete and Rapid Acetylator

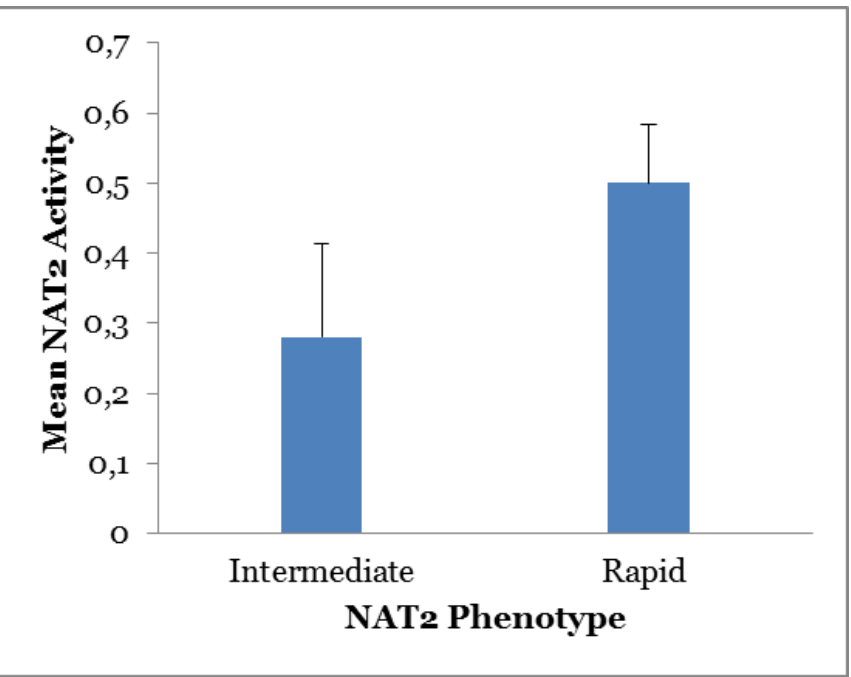

Table 1: Allele Frequency of NAT2 in the present study

\begin{tabular}{|c|c|c|c|c|c|c|c|}
\hline \multicolumn{6}{|c|}{ Haplotype } & \multirow{2}{*}{$\begin{array}{c}\text { NAT2 } \\
\text { Alleles }\end{array}$} & \multirow{2}{*}{$\begin{array}{c}\text { Frequency } \\
\text { (\%) }\end{array}$} \\
\hline 1 & 2 & 3 & 4 & 5 & 6 & & \\
\hline C & $\mathrm{T}$ & C & G & $A$ & G & NAT2* 4 & 31,7 \\
\hline C & C & T & G & G & G & NAT $2 * 5 B$ & 11,7 \\
\hline $\mathrm{T}$ & $\mathrm{T}$ & C & A & A & G & NAT $2 * 6$ A & 33,3 \\
\hline $\mathrm{T}$ & $\mathrm{T}$ & C & G & $A$ & $A$ & NAT2 $* 7 B$ & 20 \\
\hline $\mathrm{T}$ & $\mathrm{T}$ & C & G & A & G & NAT $2 * 13$ & 3,3 \\
\hline
\end{tabular}

Table 2: Acetylation ratio in samples with different NAT2 genotype

\begin{tabular}{|c|c|c|c|c|c|}
\hline $\begin{array}{l}\text { NAT2 } \\
\text { Genotype }\end{array}$ & n* & $\%$ & $\begin{array}{l}\text { Predictive } \\
\text { Phenotype }\end{array}$ & $\%$ & Activity \\
\hline$* 4 / * 4$ & 2 & 10,53 & $\begin{array}{l}\text { Rapid } \\
\text { Acetylator }\end{array}$ & 10,53 & 0.5 \\
\hline$* 4 / * 5 B$ & 2 & 10,53 & \multirow{4}{*}{$\begin{array}{l}\text { Intermediate } \\
\text { Acetylator }\end{array}$} & \multirow[t]{4}{*}{89,47} & 0.14 \\
\hline$* 4 / * 6 \mathrm{~A}$ & 8 & 42,11 & & & 0.28 \\
\hline$* 4 / * 7 \mathrm{~B}$ & 5 & 26,32 & & & 0.33 \\
\hline$* 6 \mathrm{~A} / * 13$ & 2 & 10,53 & & & 0.25 \\
\hline Total & 19 & 100 & & & \\
\hline
\end{tabular}

